\title{
Esthetic Crown Lengthening with Flapless Osseous Reduction using Abrasive Bur: A New Innovative Approach
}

\section{RM Norman Tri Kusumo Indro* and Leonard C Nelwan}

Division of Dentistry, Prof. Dr. Moestopo (Beragama) University, South Jakarta, lowa, Indonesia

*Corresponding author: RM Norman Tri Kusumo Indro, Division of Dentistry, Prof. Dr. Moestopo (Beragama) University, South Jakarta, lowa, Indonesia, Tel: + 087883307544; E-mail: normankusumo@icloud.com

Received date: November 20, 2018; Accepted date: December 19, 2018; Published date: December 28, 2018

Copyright: () 2018 Indro RMNTK, et al. This is an open-access article distributed under the terms of the Creative Commons Attribution License, which permits unrestricted use, distribution, and reproduction in any medium, provided the original author and source are credited.

\begin{abstract}
Introduction: A smile design were evaluation and analysis of both facial and dental composition. Facial driven principle like basic shape of face, incisal edge position, tooth components and gingival levels were key factor to achieving pleasing smile. In crown lengthening with open flap procedure, black triangle was the most common complication. But in some indications, it is possible to do osseous reduction in flapless approach.

Objectives: Facial driven measurement protocol and flapless osteotomy in crown lengthening will result more predictable and less risk of black triangle. This new approach provide more user friendly for clinician.

Case management: Patient come in a private practice clinic for smile esthetic complain. Face profile were long straight, insisal edge position on smiling showing more than $2.0 \mathrm{~mm}$ gingival expose, $\mathrm{F}$ and $\mathrm{V}$ test were added to determine labiolingual position. Teeth's proportion and gingival level using Chu guiding system. Sulcus and bone sounding were measured. Gummy smile and osseous reduction crown lengthening was indicated. Flapless osteotomy procedure performs to prevent black triangle. This approach where gently elevate marginal gingival through alveolar crest with gingival retractor after gingivoplasty without interfere its papilla and then perform osteotomy using small round bur until reach ideal dento-gingival complex
\end{abstract}

Conclusion: Among the benefits of this protocol were more accurate, low morbidity with no sutures, less bleeding and greater patient acceptance. The outcomes are fair result. Flapless osteotomy in Esthethic crown lengthening is one alternative minimally invasive approach which, when indicated, offers realistic clinical benefits to patients.

Keywords: Facial driven; Esthetic; Gummy smile; Crown lengthening

Abbreviations: CCL: Clinical Crown Lengthening; CEJ: CementEnamel Junction; BC: Bone Crest

\section{Introduction}

Facial driven pleasing smile is attained by establishing a balanced relationship between lips, gingiva and teeth. It is estimated that $10 \%$ of the population has excessive gingival display and most of them are women [1]. Gingival tissue in relation to the upper lip classifies the smile as low, medium or high [2]. Facial driven principle like basic shape of face, incisal edge position, tooth components and gingival levels were key factor to achieving pleasing smile. the most esthetically acceptable of the three seems to be the medium height smile in which all maxillary incisor crowns are exposed and there is display of about 1 $\mathrm{mm}$ of gingiva [1].

During crown lengthening with osseous surgery, black triangle were most of the common complication, therefore an innovate approach were needed. Treatment success is directly linked to careful diagnosis, proper determination of the causal agent and careful treatment plan that takes into account the biological distances. The presence of altered passive eruption is a clear indication of gingival smile through Clinical
Crown Lengthening (CCL), since in these cases, facial proportions, lip length and motility are normal, although there is substantial gingival display along with short clinical crowns [1].

The precise indication calling for intervention by a periodontist is the altered passive eruption [3-5]. In these cases, the facial proportions and length/motility of the upper lips are normal; however, there is an extensive exposure of the gingiva and short clinical crowns. Tooth eruption is determined by the crown emerging from the bony housing, and is finished when teeth reach the occlusal plane and occlude.

During this process, the soft tissues are also moved in the coronal direction and start to physiologically recede in the apical direction to the level of the Cement-Enamel Junction (CEJ) (passive eruption). But soft tissues don't migrate apically; it is called altered passive eruption, and is characterized by excess of coverage of the crown by the soft tissues. It can be sub-classified related to the position of the CEJ and the Bone Crest (BC) [3].

However, some cases allow a flapless procedure to be performed, i.e., via the gingival sulcus using micro chisels. This method preserves the periosteum and provides blood supply, consequently reducing early bone resorption while contributing to tissue healing. Moreover, because there is no lap, there is no need for sutures, and the postoperative period becomes faster and more comfortable for the patient [1]. 
Citation: Indro RMNTK, Nelwan LC (2018) Esthetic Crown Lengthening with Flapless Osseous Reduction using Abrasive Bur: A New Innovative Approach. Dentistry 8: 526. doi:10.4172/2161-1122.1000526

Page 2 of 3

However, some indication for our re-engineered doctor Norman and doctor Leonard approach technique were thick to very thick Gingival biotype with delayed passive eruption case, thickness of gingival more than $2 \mathrm{~mm}$, greater wide area of procedure operation, gummy smile, short teeth, uneven gingival contour and needs of bone reduction based on bone sounding check and rontgen.

This study aimed to demonstrate and indicate the re-engineered protocol for esthetic lengthening of the clinical crown by means of flapless osteotomy that can produce more predictable result [2].

\section{A Clinical Case Report}

Female patient in healthy and good systemic condition came to the private clinic of south Jakarta, Indonesia. Chef complaining was exposed gingival smile. Face profile were long straight, insisal edge position on smiling showing more than $2.0 \mathrm{~mm}$ gingival expose, $\mathrm{F}$ and $\mathrm{V}$ test were added to determine labiolingual position. Teeth's proportion and gingival level using Chu guiding system. Sulcus and bone sounding were measured (Figure 1). Altered passive eruption was diagnosed in association with gummy smile.

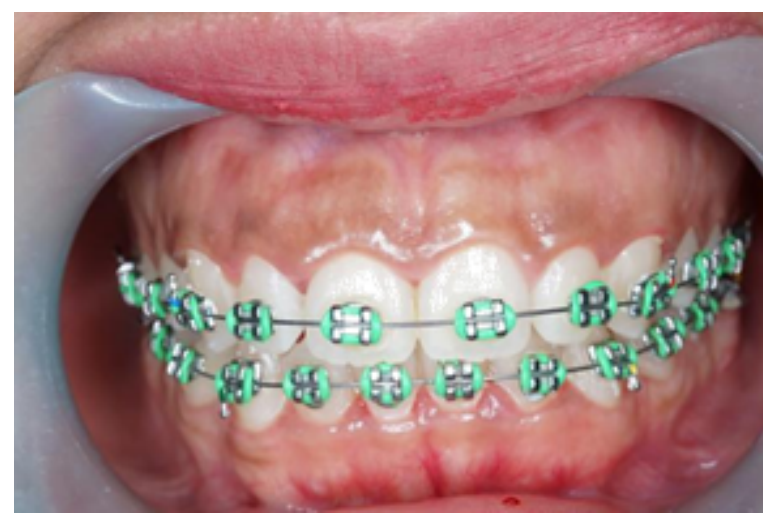

Figure 1: Initial smile.

In this case, the technique of choice was flapless esthetic CCL. Gingivectomy was performed marked according to the CEJ, which is identified with an exploratory probe and measured with a millimeter probe (Figure 2). After gingivectomy (Figure 3), probe was once again used to measure the distance from the gingival margin to the $\mathrm{BC}$ or bone sounding checking (Figure 4), which should ideally be $2 \mathrm{~mm}$ according to dento gingival complex. If the distance is shorter than recommended, then proceed to perform an osteotomy using abrasive $10 \mathrm{~mm}$ carbide flutted bur gently guard the gingival from the rotary instrument using mini gingival retractor (Figure 5). To check the distance between the new gingival margin and the alveolar crest the site was once again probed at the end of the surgery. Gauze compression is done to stop any bleeding. No sutures or dressing are necessary (Figure 6).

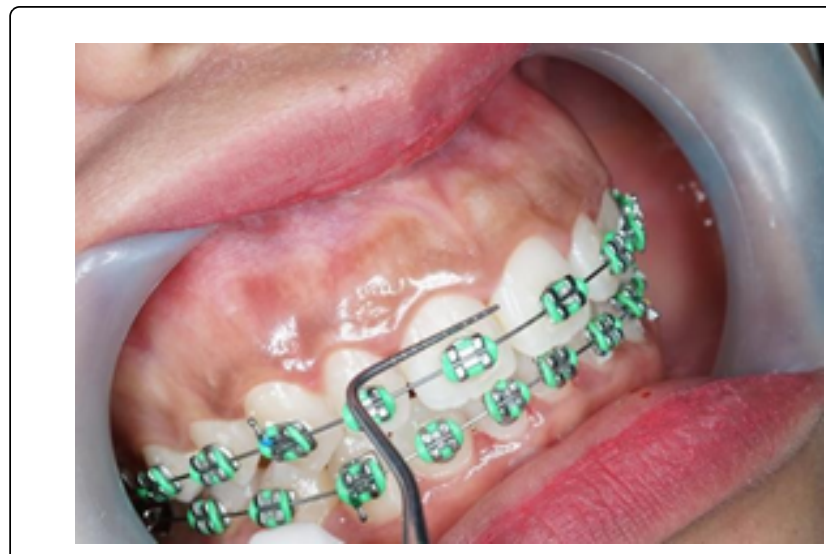

Figure 2: Exploratory probe and measured with a millimeter probe.

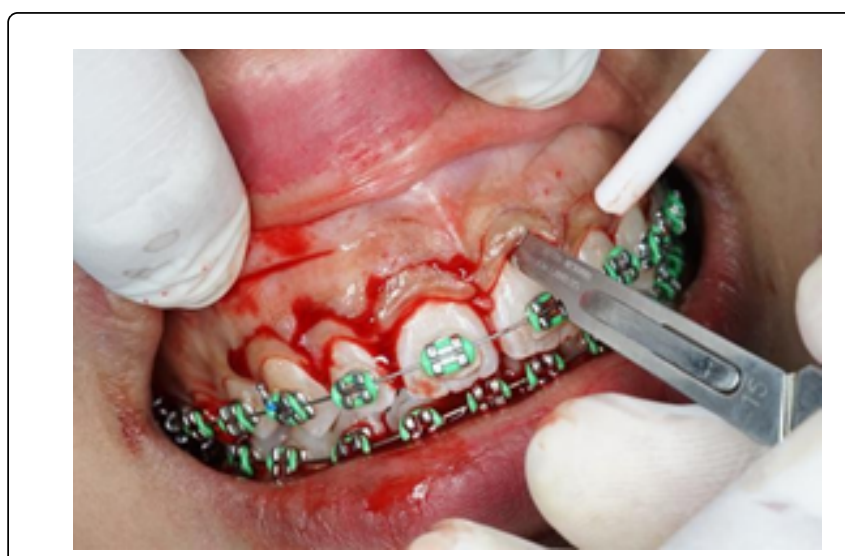

Figure 3: Gingivectomy was performed.

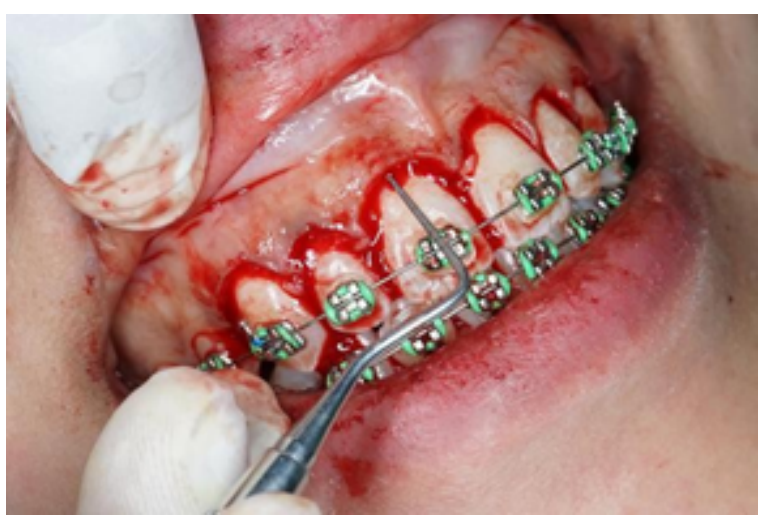

Figure 4: After gingivectomy, probe was once again used to measure the distance from the gingival margin to the BC. 


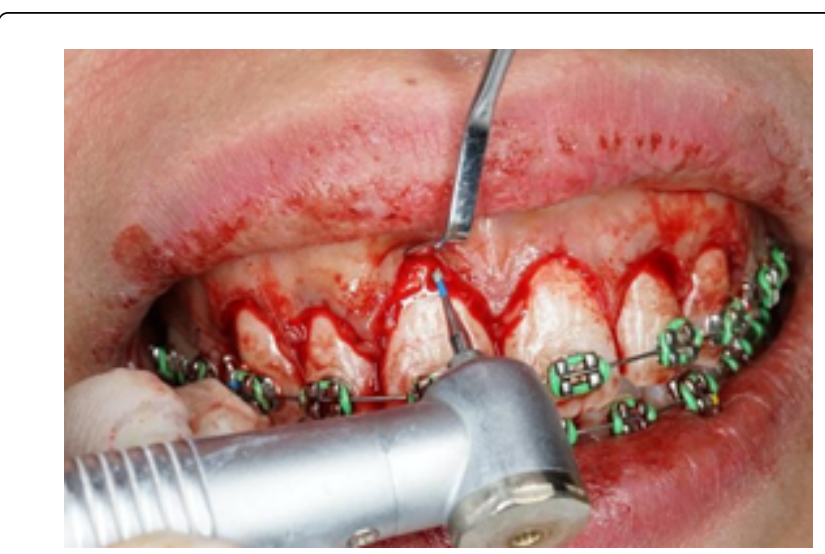

Figure 5: Osteotomy using abrasive $10 \mathrm{~mm}$ carbide flutted bur gently guard the gingival from the rotary instrument using mini gingival retractor.

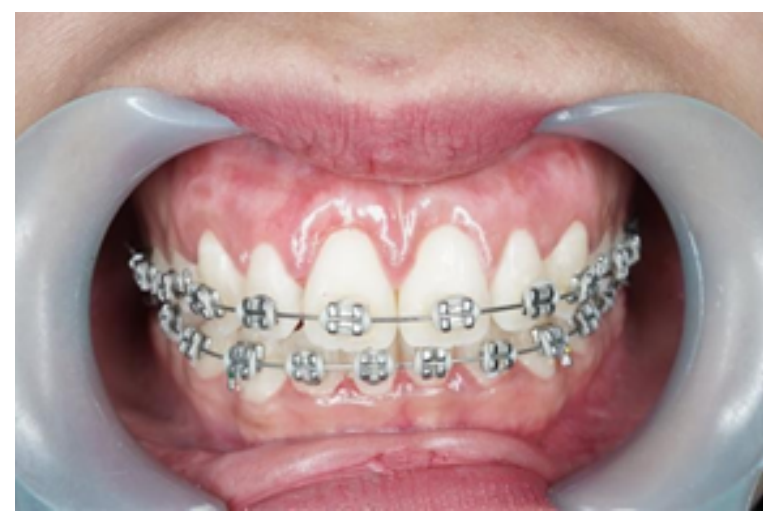

Figure 6: 120 days after operation control.

\section{Discussion}

Facial driven protocol added in the treatment planning for aesthetic crown lengthening has to take into the necessity or otherwise of associated prosthetic rehabilitation. In clinical situations if indicated the determination of the future prosthetic margin should match the gingival margin contours and will eventually orient the extent of osteotomy.

In these cases, flapless ostectomy were result good result with predictable preparation and impression. The gingival sulcus seems to be completely established after 3 months, but complete healing of the tissues can take up to a year depending of characteristics of the initial surgery.

The main advantages over traditional apical flap in crown lengthening techniques are faster surgical time, reduce risk of black triangle, and tissue repair optimization. In contrast, non-visualization of the $\mathrm{BC}$ requires great skill on the part of the surgeon. Furthermore, it is important to emphasize that this is an extremely delicate technique and should therefore additional tools will be benefit in order to avoid tears in the soft tissue when abrasive bur in ostectomy.
However, or main goal is to develop a new protocol approach indicate that not all patients are suitable for this technique since there are different periodontia. For thick gingival type, flap elevation is needed because in addition to osteotomy it is also necessary to reduce bone thickness (osteoplasty).

The distance between the CEJ and BC determines the need or otherwise for osteotomies. Traditionally, osteotomy and osteoplasty are performed after a flap elevation for full exposure of the bone. In our understanding, this is valid for thick tissue biotype in which osteoplasty (thickness removal) is recommended to improve the bone architecture and the adaptation of the tissues.

In clinician, indication in tissue biotypes, especially in the premaxilla and therefore, in most clinical situations, osteoplasty is not necessary. This means flap elevation in such cases is not strictly necessary. Obviously, the so-called flapless procedure is technically sensitive, so a course of learning is necessary to master it without tearing the soft tissues. Besides this, without elevating the flap it is more difficult to orient the shape of the osteotomy. The use of the probe to measure the distance of the $\mathrm{CEJ}$ and the $\mathrm{BC}$ through the sulcus along the margin is essential to evaluate the accuracy of these techniques [6,7].

\section{Conclusion}

The use of a flapless surgical technique whereby the CCL reduces tissue healing time, local inflammation and consequently postoperative discomfort.

Among the benefits of this protocol were more accurate, low morbidity with no sutures, less bleeding and greater patient acceptance. The outcomes are fair result. Flapless osteotomy in Esthethic crown lengthening is one alternative minimally invasive approach which, when indicated, offers realistic clinical benefits to patients but the proper indications of this procedure have to be carefully guided the re-engineered facial driven protocol (thin or intermediate biotypes/abundant keratinized tissue) in order to achieve stable and aesthetic outcomes.

\section{References}

1. Cesar JJ, Mesquita De Carvalho PF, Da Silva CR (2011) Flapless aesthetic crown lengthening: A new therapeutic approach. $R$ Mex de Periodontologia 2.

2. Corrêa BB, Passoni BB, Souza JGO, Pereira Neto ARL, Benfatti CAM (2014) Correcting gingival smile through flapless osteotomy: Predictability with minimal morbidity. Dental Press Implantol 8: 64-69.

3. Gupta GD, Gupta R, Gupta N, Gupta U (2015) Crown Lengthening procedures-A Review article. IOSR-JDMS 14: 27-37.

4. Lavere AM (1992) Denture tooth selection: An analysis of the natural maxillary central incisor compared to the length and width of the face. J Prosthet Dent 67: 661-663.

5. Pound E (1983) Personalized denture procedures. Dentist Manual. Denar Corhup.

6. Bloom DR, Padayachy JN (2006) Increasing occusal vertical dimensionWhy, When, How. Br Dent J 200: 251-256.

7. Chu SJ, Tan JH, Stappert CF, Tarnow DP (2009) Gingival Zenith position and levels of the maxillary anterior dentition. J Esthett Restor Dent 21: 113-120. 